\title{
QUANTIFICAÇÃO DE ÁGUA EM CARCAÇAS CONGELADAS DE FRANGO, COMERCIALIZADAS EM RIO BRANCO, ACRE
}

Adriano Melo de Queiroz ${ }^{1}$, Henrique Jorge de Freitas ${ }^{2}$, Cássio Toledo Messias ${ }^{3}$, Bruna Laurindo Rosa ${ }^{4}$, Edivaldo Nunes Gonçalo ${ }^{5}$

\begin{abstract}
${ }^{1}$ Mestrando no Programa de Pós-Graduação em Sanidade e Produção Animal Sustentável na Amazônia Ocidental - PPGESPA na Universidade Federal do Acre,

Rio Branco, Acre, Brasil. email: queiroz_adriano@yahoo.com.br

${ }^{2}$ Professor Doutor do Centro de Ciências Biológicas e da Natureza- CCBN pela Universidade Federal do Acre no campus de Rio Branco, Acre, Brasil,

${ }^{3}$ Doutorando no Programa de Pós-Graduação em Sanidade e Produção Animal Sustentável na Amazônia Ocidental- PPGESPA e professor mestre da Universidade

Federal do Acre, campus de Rio Branco, Acre, Brasil.

${ }^{4}$ Professora Doutora do Centro de Ciências Biológicas e da Natureza - CCBN da Universidade Federal do Acre no campus de Rio Branco, Acre, Brasil,

${ }^{5}$ Médico Veterinário pela Universidade Federal do Acre, Rio Branco, Acre, Brasil,
\end{abstract}

Recebido em: 02/10/2017 - Aprovado em: 21/11/2017 - Publicado em: 05/12/2017 DOI: 10.18677/EnciBio_2017B55

A introdução excessiva de água em carcaças congeladas de frango é um problema que afeta diretamente os consumidores e que só pode ser combatido por meio de uma eficiente fiscalização. Desse modo, o presente trabalho teve por objetivo avaliar o teor de água contido em carcaças congeladas de frango das principais marcas comercializadas nos supermercados da cidade de Rio Branco - Acre, através do método Drip test, e também verificar a diferença percentual de água entre carcaças de tamanho pequeno, médio e grande. $O$ experimento foi realizado no laboratório de Anatomia Animal da Universidade Federal do Acre no período de 13 a 15 de julho de 2015. Foram avaliadas carcaças de 3 marcas comerciais, divididas de acordo com o peso: marca $A$ (carcaças pequenas) marca $B$ (carcaças médias) e Marca $C$ (carcaças grandes). Para cada marca foi coletada uma amostra de seis carcaças de frango congelado, vindas de mesmo lote, perfazendo um total de 18 carcaças de aves. Foi possível constatar que as carcaças congeladas da Marca B (33,33\% das marcas analisadas) possuem teor de água acima do limite de $6 \%$ estabelecido pelo Ministério da Agricultura Pecuária e Abastecimento (MAPA) e que as Marcas A e C $(66,66 \%)$ se encontram dentro do limite aceitável. O presente estudo permite concluir que existem carcaças congeladas de frango sendo comercializadas na cidade de Rio Branco em situação de fraude, e que não há relação entre o tamanho da carcaça e a quantidade de água absorvida nas etapas de processamento.

PALAVRAS -CHAVE: Aves; descongelamento, drip test, teor de água. 


\title{
QUANTIFICATION OF WATER IN FROZEN CHICKEN CARCASSES, COMMERCIALIZED IN RIO BRANCO, ACRE
}

\begin{abstract}
Excessive introduction of water into frozen chicken carcasses is a problem that directly affects consumers and can only be fought efficient surveillance. The objective of this study was to evaluate the content of water contained in frozen chicken carcasses of the main brands marketed in supermarkets in the city of Rio branco Acre, using the Drip test method, and also to verify the percentage difference of water between carcasses of small, medium and large size. The experiment was carried out in the animal anatomy laboratory of the Federal University of Acre from July 13 to 15,2015 . Carcasses of three commercial brands were evaluated, divided according to the weight: brand A (small carcasses) brand B (averages carcasses) and Brand C (large carcasses). For each mark, a sample of six frozen chicken carcasses from the same lot was collected, making a total of 18 poultry carcasses. It was possible to verify that the frozen brand B carcasses $(33.33 \%$ of the analyzed brands) have a water content above the $6 \%$ limit established by established by the Ministry of Agriculture Livestock and Supply (MAPA) and that Marks A and C (66, $66 \%)$ are within acceptable limits. The present study allows to conclude that there are frozen chicken carcasses being commercialized in the city of Rio branco in a situation of fraud, and that there is no relation between the size of the carcass and the amount of water absorbed in the processing stages.
\end{abstract}

KEYWORDS: Birds, Drip test, water content, thawing.

\section{INTRODUÇÃO}

Nos últimos anos a avicultura brasileira tem se desenvolvido de forma bastante intensa, como resultado a incorporação de tecnologias pelo setor, possibilitando ganhos de produtividade, sobretudo, através da melhora dos índices de conversão alimentar, do ganho nutricional, da pesquisa em genética, da maior automação dos aviários e de melhor manejo executado durante os processos.

De acordo com a Associação Brasileira de Proteína Animal - ABPA, o Brasil é o segundo maior produtor mundial de carne de frango, com 12.900 mil toneladas produzidas, estando atrás somente dos Estados Unidos com valores acima de 18.000 mil toneladas, deixando para traz países como China que até o ano de 2015 ocupava a segunda posição, seguida de União Europeia e Índia. Já na lista dos maiores exportadores o país lidera o ranking mundial, ocupando o primeiro lugar, com 4.384 mil toneladas exportadas (ABPA, 2017).

A carne de frango é uma importante e acessível fonte de proteína animal disponível para o consumo da população humana. O baixo custo aliado ao seu excelente valor nutricional foram fatores preponderantes para o desenvolvimento e consolidação do mercado promissor dentro e fora do país. Atualmente o consumo percapta brasileiro vem aumentando e é da ordem de $41,10 \mathrm{Kg} / \mathrm{hab} / \mathrm{ano}$ embora ainda, esteja um pouco abaixo do pico máximo de consumo, registrado no ano de 2011 que foi de 47,38 Kg/hab/ano (ABPA, 2017).

Um dos pontos que merece atenção permanente dos consumidores, indústria e principalmente órgãos fiscalizadores é o caso da introdução excessiva de água à carcaça e aos cortes de frango. Esse problema pode ocorrer durante uma das etapas mais importantes do processo de abate, o resfriamento, que consiste na 
imersão da carcaça em água gelada, visando com isso, reposição da água perdida nos processos anteriores e, principalmente, a proteção da peça na etapa subsequente, o congelamento.

Para evitar possíveis fraudes que possam ocorrer durante esse processo, são realizadas análises para verificar o teor de líquido absorvido, conforme preconiza a Portaria ํㅡㄹㅡ 210, de 10 de novembro de 1998 do Ministério da Agricultura, Pecuária e Abastecimento - MAPA, que estabelece os limites de $8 \%$ do peso da carcaça no método de controle interno e de $6 \%$, no método do gotejamento (Drip test).

A fiscalização na indústria de forma isolada não é suficiente para combater esse problema. Neste contexto, torna-se necessária a verificação também no comércio, pois esse tipo de fraude vem ocorrendo em diversas cidades do Brasil.

Diante disso, o presente trabalho teve como objetivo realizar um estudo, com carcaças de frango congeladas com miúdos e cortes das principais marcas comercializadas nos supermercados de Rio Branco - Acre, utilizando o procedimento de "Drip test" e assim verificar a diferença percentual de água entre carcaças pequenas, médias e grandes, e a existência de carcaças congeladas de frango com teor de água em desacordo com a legislação vigente.

\section{MATERIAL E MÉTODOS}

O experimento foi realizado no laboratório de Anatomia Animal da Universidade Federal do Acre - UFAC campus sede, Rio Branco - AC, no período de 13 a 15 de julho de 2015.

As carcaças congeladas de frango foram adquiridas e coletadas em três dos principais supermercados de Rio Branco - AC. Após a coleta no supermercado, as mesmas foram colocadas em uma caixa de isopor com gelo em cubo e transportadas até o freezer do laboratório, onde foram mantidas à temperatura de $12{ }^{\circ} \mathrm{C}$ por um período de 24 horas, até o momento da análise.

Neste trabalho, utilizou-se carcaças provenientes de três marcas distintas, sendo que, para cada marca foram coletadas amostras de seis carcaças de frango congelado, vindas do mesmo lote, perfazendo um total de 18 carcaças.

Os tratamentos foram designados da seguinte forma: marca $A=$ carcaças pequenas, com massa variando de 930 a $1039 \mathrm{~g}$; marca $B$ = carcaças médias, com massa variando de 1920 a 1977g; e marca $C=$ carcaças grandes, com massa variando de 2843 a $3046 \mathrm{~g}$.

Para avaliar a porcentagem de água nas massas das carcaças congeladas com miúdos e partes comestíveis, foi utilizado o método do gotejamento "Drip test" de acordo com o anexo I da Portaria № 210 de 1998 do Ministério da Agricultura Pecuária e Abastecimento.

Inicialmente, as amostras foram retiradas do congelador. O lado externo da embalagem foi enxugado com papel toalha, de modo a eliminar todo o líquido e gelo. Em seguida, foi feito a pesagem da carcaça com a embalagem em balança digital com capacidade para 5,0 Kg. Com isto, se obteve a medida denominada "M0". Em seguida, a ave congelada (com as vísceras no seu interior) foi retirada de dentro da embalagem, sendo essa enxugada com papel toalha e pesada, obtendo-se assim a medida "M1". A massa da carcaça de frango foi igual a "M0" - "M1".

Após o procedimento inicial, a ave congelada com as vísceras foi colocada dentro de um saco plástico com o abdômen voltado para o fundo do mesmo. Este foi fechado para que a água não penetrasse no seu interior. Em seguida, o saco 
contendo a carcaça foi imerso em banho de água a $42{ }^{\circ} \mathrm{C} \pm 2{ }^{\circ} \mathrm{C}$ com monitoramento constante, até que a temperatura do centro da ave atingisse $4^{\circ} \mathrm{C}$.

Para a determinação do tempo de imersão da carcaça das aves no banho, utilizou-se os parâmetros apresentados na Tabela 1.

TABELA 1. Tempo de imersão da carcaça no banho em função da massa.

\begin{tabular}{cc}
\hline Massa da ave mais vísceras $(\mathrm{g})$ & Tempo de imersão (min) \\
\hline Até 800 & 65 \\
801 a 900 & 72 \\
901 a 1.000 & 78 \\
1.001 a 1.100 & 85 \\
1.101 a 1.200 & 91 \\
1.201 a 1.300 & 98 \\
1.301 a 1.400 & 105 \\
1.401 a 1.500 & 112 \\
1.501 a 1.600 & 119 \\
1.601 a 1.700 & 126 \\
1.701 a 1.800 & 133 \\
1.801 a 1.900 & 140 \\
1.901 a 2.000 & 147 \\
2.001 a 2.100 & 154 \\
2.101 a 2.200 & 161 \\
2.201 a 2.300 & 168
\end{tabular}

Fonte: BRASIL (1998)

Nota: Acima de 2.300 gramas, aumenta-se o tempo de permanência no banho em sete minutos para cada $100 \mathrm{~g}$ adicionais na massa de ave.

Após o período de imersão, os sacos plásticos foram retirados do banho e colocados sobre bandejas, foi aberto um orifício na parte inferior dos mesmos, de modo, que se permitiu o escoamento da água do degelo. Em seguida, a embalagem e seu conteúdo foram deixados à temperatura ambiente $\left(18\right.$ a $25^{\circ} \mathrm{C}$ ) por uma hora. Após o descongelamento, as carcaças foram retiradas do saco, bem como as vísceras que estavam no seu interior, sendo então, as carcaças enxugadas interna e externamente com papel toalha. Após esse procedimento, os invólucros das vísceras foram perfurados, de modo que a água do seu interior pudesse escoar e os mesmos secarem. Posteriormente, os mesmos ainda foram enxugados com papel toalha, visando com isso, assegurar a secagem final.

Após a secagem, as carcaças descongeladas, juntamente com as vísceras foram pesadas, obtendo-se assim, a medida "M2". Depois disso, foram pesados os invólucros que continham as vísceras, obtendo-se então a medida "M3".

Para o calculo de \% de líquido perdido da ave congelada, foi utilizada a fórmula proposta pela portaria $n^{\circ} 210 / 1998$ do MAPA (BRASIL, 1998).

$\%$ de Liquido perdido $=\frac{\text { MO-M1-M2 }}{\text { MO-M1-M3 }} \times 100$ 
Onde: $\mathrm{M0}=$ Massa bruta da carcaça com suas vísceras e embalagens.

M1 = Massa da embalagem primária da carcaça.

M2 = Massa da carcaça descongelada e suas vísceras com embalagem.

M3 = Massa dos invólucros que embalavam as vísceras.

Para verificação da quantidade de água por lote, utilizou-se a média de água absorvida entre seis carcaças, e nos casos que essa média superou o limite de $6 \%$, considerou-se, que a quantidade de água absorvida durante o processo de imersão ultrapassa o valor máximo estabelecido pelo MAPA, e portanto, encontra-se em situação de fraude econômica (BRASIL, 1998).

A análise estatística foi realizada utilizando o programa computacional SISVAR (FERREIRA, 2010); e a comparação de médias foi realizada pelo teste de Tukey ao nível de $5 \%$ de significância.

\section{RESULTADOS E DISCUSSÃO}

Não foi observada diferença significativa $(P>0,05)$ entre as médias de agua das carcaças analisadas conforme pode ser observado na tabela 2 .

TABELA 2 - Quantidade de água (\%) das amostras e marcas avaliadas.

\begin{tabular}{cccc}
\hline Amostras/Marca & Marca A (\%) & Marca B (\%) & Marca C (\%) \\
\hline 1 & 4,46 & 6,75 & 5,39 \\
2 & 4,75 & 5,49 & 5,79 \\
3 & 6,51 & 5,08 & 5,50 \\
4 & 6,94 & 6,12 & 7,55 \\
5 & 4,10 & 5,43 & 6,18 \\
6 & 4,01 & 7,68 & 4,38 \\
\hline Média & $5,13 a$ & $6,10 a$ & $5,80 a$
\end{tabular}

Médias seguidas de mesma letra na linha não diferem estatisticamente entre si, pelo teste de Tukey ao nível de $5 \%$ de probabilidade $(P>0,05)$.

Os resultados do "Drip test" das amostras de carcaças pequenas de frangos (Marca A), obtidas nos supermercados de Rio Branco, demonstraram que duas amostras apresentarem indícios de fraude (Tabela 2), no entanto, a média de água contida no lote analisado através do "Drip test", está de acordo com a legislação, obedecendo ao limite de $6 \%$ (Tabela 1).

Por outro lado, é possível observar que para o lote de tamanho médio (Marca B), os dados obtidos indicam a ocorrência de fraude econômica nestas carcaças, tendo em vista que o valor médio do lote supera o limite de $6 \%$ estabelecido pela legislação. Na mesma análise, observa-se que três amostras encontram-se acima desse valor de referência.

$\mathrm{Na}$ analise de "Drip test" de carcaças de frango congelados de tamanho grande (Marca C), os resultados obtidos indicam que o lote em avaliação encontrase conforme a legislação vigente (Tabela 2), no que se refere ao conteúdo de água absorvido durante o pré-resfriamento da carcaça, muito embora a média do mesmo esteja próxima do limite máximo tolerável e que duas amostras estejam acima desse valor.

Das três marcas analisadas uma encontra-se em situação de fraude econômica (marca B), excedendo o limite máximo de $6 \%$ estabelecido pela instrução 
normativa $\mathrm{n}^{0} 210$ de 1998 do MAPA, o que representa 33,33\% das marcas avaliadas.

Com este resultado foi possível verificar que o lote que possui maior porcentagem de água é o Médio, seguido do Grande e posteriormente, do Pequeno. Diferentemente da hipótese levantada por Santos et al. 2013, que há uma tendência de maior absorção de água (em percentual) por carcaças de menor massa.

Quando as médias foram comparadas, observou-se que apesar da ocorrência de diferença numérica, não houve diferença significativa $(P>0,05)$ entre as mesmas (Tabela 3). Indicando com isso, que o tamanho da carcaça não influência na quantidade de água absorvida durante o processamento.

TABELA 3. Resultado da análise de "Drip test" de carcaças de frango congelado de tamanho pequeno, médio e grande, coletados nos supermercados de Rio Branco - AC.

\begin{tabular}{lcc}
\hline Marca (tamanho) & Média (\%) & $\begin{array}{c}\text { Desvio Padrão da } \\
\text { Média }\end{array}$ \\
\hline A (Pequena) & $5,13 \mathrm{a}$ & 1,2719 \\
B (Média) & $6,10 \mathrm{a}$ & 0,9778 \\
C (Grande) & $5,80 \mathrm{a}$ & 1,0470 \\
\hline CV \% & 19,5 & \\
\hline
\end{tabular}

Médias seguidas de mesma letra na coluna não diferem estatisticamente entre si, pelo teste de Tukey ao nível de $5 \%$ de probabilidade $(P>0,05)$.

Observando individualmente as amostras de cada lote, verifica-se que das 18 carcaças analisadas, 7 (38,89\%) encontram-se com percentual de água acima do limite estabelecido (Tabela 2). Resultado que demonstra um alto índice de sobrepeso de água nas carcaças analisadas. Fato esse que pode estar relacionado tanto a inabilidade de controle técnico por parte da empresa durante as etapas de processamento, como a também a possíveis ações intencionais da indústria no sentido de obter maior ganho financeiro.

Verifica-se também a existência de variações de teor de água entre carcaças do mesmo lote e entre as marcas analisadas (Tabela 2). Indicando com isso, uma certa desuniformidade na absorção de água mesmo em carcaças de gramatura semelhante, o que permite inferir que a indústria produtora da marca $\mathrm{B}$, possui maior controle do índice de absorção de água em seus produtos, tendo em vista que foi a marca que possui menor desvio padrão da média (Tabela 1) e em tese tem ciência da fraude praticada.

O alto índice de absorção de água em carcaças de frango congelados pode ser justificado por fatores que estão relacionados desde a fase de pré-abate até o processamento. De acordo com Kato et al. (2013), fatores como condição pré-abate, que resultam em carne PSE influenciam nos resultados do "Drip test", sendo que a violação neste caso não deveria ser considerada fraude industrial, tendo em vista que nessas condições, a carne tem pouca capacidade de retenção de água, o que no caso, deveria ser considerado uma não conformidade da matéria prima e não uma fraude. Sendo que para isso a legislação devia também considerar como variável o $\mathrm{pH}$ das carcaças. 
A etapa de resfriamento, por sua vez é a que mais influencia na absorção de água, tendo em vista que nela os frangos são submetidos a diversas lavagens e submersas em taques com água fria. Desse modo, fatores como tempo de imersão, temperatura da água no final do chiller, pressão hidrostática e agitação da água (borbulhamento) este último proibido, são condições determinantes da quantidade de água absorvida pelas carcaças de ave durante o arrefecimento (CARCIOFI; LAURINDO 2007; BAILONE; ROÇA, 2017).

A imersão no tanque de água fria (chiller) tem a finalidade de promover 0 abaixamento da temperatura das carcaças, visando com isso, reduzir proliferação microbiana. No entanto, esse processo pode aumentar o conteúdo de água absorvido pelo músculo da ave, elevando a massa da carcaça em relação ao seu valor inicial (ÇENGEL, 2012; SIMAS et al. 2013; BAILONE; ROÇA, 2017).

Outra variável que também exerce influencia na absorção de água na carcaça de frango, é o tempo de permanência das carcaças na linha de gotejamento, que deve ser de no mínimo 3 minutos, tendo em vista que esse procedimento visa eliminar o excesso de água absorvido nas operações de pré-resfriamento e resfriamento por imersão, onde o valor absorvido ao final do gotejamento, não pode ultrapassar o limite máximo de $6 \%$ sua massa inicial (BRASIL, 1998).

A velocidade e o tempo de congelamento também podem influenciar na quantidade de água absorvida. Haja vista que, no congelamento lento ocorre a formação de cristais de água na área extracelular, que aumentam à medida que a água da célula atravessam as membranas, pelo mecanismo da osmose. Posteriormente, em razão do aumento do volume dos cristais e do encolhimento das fibras musculares a célula, sofre um dano mecânico, perdendo água para o meio externo, ocasionando com isso, uma maior perda de água ou drip durante a descongelação (PARDI et al., 1993).

Outro fator que também corrobora na incidência dessa problemática, é a velocidade dos chillers de resfriamento, pois quanto menor, maior será o resultado do "Drip test". De acordo com Nascimento et al. (2014), a velocidade deve ser ajustada para permitir a permanência das carcaças por um tempo de aproximadamente 42 minutos e uma absorção dentro do limite de $6 \%$.

Ainda de acordo com o mesmo autor, a ocorrência de variações na temperatura do resfriamento influencia na quantidade de absorção de água, o que pode resultar em resultados de "Drip test" acima do estabelecido por lei.

No entanto, cabe ressaltar que a incorporação de água no frango, muitas vezes é feita de forma fraudulenta pelas empresas, que se aproveitam de falhas na fiscalização, com o objetivo de obter vantagens econômicas no comércio, através do peso final do produto, ocasionando com isso, prejuízos à economia popular (GARNICA et al., 2014; SILVA et al., 2017).

A ocorrência de lotes de frangos congelados em situação de fraude, tem sido identificada em diversas localidades do país. Essa constatação, pode estar relacionada a fatores como: excesso de permanência da carcaça do chiller, redução de tempo da carcaça no gotejamento, bem como, a ocorrência de estresse préabate. Motivadas de maneira intencional ou simplesmente por baixa capacidade técnica da empresa no controle de variáveis como temperatura e velocidade das operações de abate e processamento.

Dentre os cuidados que as empresas devem tomar para manter os produtos dentro do limite ideal destacam-se: o controle da temperatura e renovação periódica dos tanques de resfriamento; o tempo de permanência das carcaças no chiller; 
padronização do tamanho e idade das aves, e o congelamento rápido dos produtos. (BRIZIO et al., 2012).

Gomes e Azeredo (2009), em trabalho realizado entre abril de 2004 a março de 2005 com 47 amostras congeladas de frango comercializadas na cidade do Rio de janeiro, constataram que $68 \%$ das mesmas estavam fora dos padrões regulamentares. De forma semelhante, Silva et al. (2017) ao analisarem 48 amostras comercializadas na microrregião de Redenção, no Pará, identificaram que destas, 97,9 \% obtiveram percentual de hidratação acima do permitido.

Nesse sentido, Santos et al. (2014) ao analisarem pelo teste do gotejamento sete marcas expostas à venda nos supermercados de São Luís, Maranhão, constataram que, apenas duas, o que corresponde a $28,6 \%$ das marcas analisadas apresentaram resultado satisfatório. As demais (71,4\%), apresentaram percentual acima dos limites legais estabelecidos.

Por outro lado, Garnica et al. (2014) ao avaliarem o teor de hidratação durante os anos de 2011 a 2012, de amostras provenientes de quatro abatedouros sob inspeção estadual no estado de São Paulo, verificaram que somente $4,44 \%$ das mesmas, possuíam valores acima do limite aceitável. Indicando com isso, um bom controle técnico por parte das empresas monitoradas.

Os resultados observados demonstram que, o teor de água em carcaças congeladas de frango pode variar dependendo da região, da marca e do lote produzido. Cabe com isso, alertar os consumidores e os órgãos de fiscalização para a necessidade de avaliação constante desse tipo de produto, sendo recomendado para isso, o monitoramento de diferentes lotes de mesma marca, em diferentes intervalos de tempo.

\section{CONCLUSÕES}

O presente estudo permite concluir que existem carcaças congeladas de frango sendo comercializadas na cidade de Rio Branco-Acre em situação de fraude; e que não há relação entre o tamanho da carcaça e a quantidade de água absorvida no pré-resfriamento por imersão.

\section{REFERENCIAS}

ABPA - Associação Brasileira de Proteína Animal. Relatório Anual da ABPA 2017. 2017. Disponível em:<http://abpa-br.com.br/storage/files/3678c_final_abpa_ relatorio_anual_2016_portugues_web_reduzido.pdf> Acessado em; 20 de agosto de 2017.

BAILONE, R. L.; ROÇA, R. O. Tendências no processamento de frangos de corte: uso racional da água. Engenharia Sanitária Ambiental, v.22 n.1, p. 65-72, jan.-fev. 2017. Disponível em: <http://dx.doi.org/10.1590/s1413-41522016154650> Acesso em: 25 de set. de 2017.

BRASIL. Ministério da Agricultura. Portaria no 210 de 10 de novembro de 1998. Aprova o regulamento técnico da inspeção tecnológica e higiênico-sanitária de carne de aves. Diário Oficial da União, Brasília, 26 de novembro de 1998. Seção I, p. 226.

BRIZIO A. P. R.; FAGUNDES, G, A.; PRENTICE, C. Avaliação quantitativa do teor de água contido em cortes congelados de frango. Revista Brasileira de Pesquisa ENCICLOPÉDIA BIOSFERA, Centro Científico Conhecer - Goiânia, v.14 n.26; p.580 2017 
em Alimentos, Campo Mourão, PR, v.3, n.1, p. 69-71, Jan./Jun., 2012. Disponível em:<https://periodicos.utfpr.edu.br/rebrapa/article/viewFile/3368/2284> Acesso em15 de Set. de 2017.

CARCIOFI, B. A. M.; LAURINDO, J. B. Water up take by poultry carcasses during cooling by water immersion. Chemical Engineeringand Processing, Florianópolis, v. 46, n. 5, p. 444-450, Jan./May. 2007. Disponível em: < https://doi.org/10.1016/j.cep.2006.05.020> Acesso em: 14 de nov. de 2017.

ÇENGEL Y. A. Transferência de Calor e Massa: Uma Abordagem Prática. 4. ed. Tradução Lino FAM. São Paulo, SP: McGraw-Hill Interamericana do Brasil Ltda., 2012. p. 271.

FERREIRA, D. F. SISVAR - Sistema de análise de variância. Versão 5.6. Lavras, MG: UFLA, 2010.

GARNICA, M. F.; ROSSI, G. A. M.; GONÇALVES, A. C. S.; AGUILAR, C. E. G.; ALMEIDA, H. M. S.; MARTINS, A. M. C. V. Avaliação das perdas de líquido por degelo de frangos congelados (Drip Test) em abatedouros. Revista Brasileira de Ciência Veterinária, v. 21, n. 1, p. 64-66, jan./mar.2014.Disponível em: < http://dx.doi.org/10.22409/rbcv.v21i1.564> Acesso em: 14 de nov. de 2017.

GOMES, V. L. M.; AZEREDO, D. P. Avaliação do teor de água em frangos congelados comercializados no Rio de Janeiro, pelo método de gotejamento (Drip Test). Revista Higiene Alimentar, v. 23, n. 168/169, p.138-145, 2009. Disponível em: < http://higienealimentar.com.br/edicoes/qualidade-do-ambiente-e-dosalimentos-a-interacao-indispensavel-80.html> Acesso em 14 de nov. de 2017.

KATO T, BARBOSA, C. F.; IDA, E. I.; SOARES, A. L.; SHIMOKOMAKI, M.; PEDRAO, M. R. Broiler chicken PSE (Pale,Soft, Exsudative) meat and water release during chicken Carcass Thawing and Brazilian legislation. Brazilian Archieves of Biology and Technology. v. 56, n. 6, p. 996-1001, 2013. Disponível em:<http://dx.doi.org/10.1590/S1516-89132013000600015> Acesso em: 14 de set. de 2017.

NASCIMENTO, J. C.; FERNANDA, C. G.; ALECIR, S. Utilização de ferramentas estatísticas no controle da absorção de água: estudo em um frigorífico de minas gerais. INOVAE - Journal of Engineeringand Technology Innovation, São Paulo, v. 2, n. 3, p. 95-111, set./dez., 2014. Disponível em: <http://www.revistaseletronicas. fmu.br/index.php/inovae/article/download/398/729> Acesso em: 17 de set de 2017.

PARDI, M. C.; SANTOS, I. F.; SOUZA, E. R.; PARDI, H. S. Ciência, higiene e tecnologia da carne. Goiânia: CEGRAF-UFG; Niterói: EDUFF, 1993. 1 v., p.528.

SANTOS, A. F.; CONCEIÇÃO S. I. O.; MONTEIRO, S. G.; PADILHA, L. L. Índice de absorção de água em carcaças de frangos congeladas comercializadas em São Luís, MA. Revista Higiene Alimentar. v. 28, n.230/231, p.147-152, mar./abr. 2014. Disponível em:< http://higienealimentar.com.br/edicoes/evolucao-das-panificadoras- 
treinamento-dos-manipuladores-e-essencial-117.html> Acesso em 14 de nov. de 2017.

SANTOS, D. V. S.; SOARES E BARROS, L. S.; MASCARENHAS, M.T.L.V.; LIMA, K. C. Evaluationofdrip test samplingplan in carcasses offrozenbroilers. International Journal of Poultry Science, v. 12, n. 11, p. 628-634, 2013. Disponível em: <http://dx.doi.org/10.3923/ijps.2013.628.634> Acesso em: 28 de set. de 2017.

SIMAS, V. S.; SANTOS, F. F.; GOUVÊA, R.; AQUINO, M. H. C.; ABREU, D. L. da C.; NASCIMENTO, E. R.; PEREIRA, V. L. de A. Pré-resfriamento na redução de coliformes em carcaças de frango de corte. Ciência Rural, Santa Maria, v.43, n.9, p.1618-1622, set, 2013.

SILVA, H. C. F.; SILVA, M. D. F.; SABINO, L. A. Teor de hidratação de carcaças de frangos de corte congelados comercializados na microrregião de Redenção- Pará. Nutritime Revista Eletrônica, on-line, Viçosa, v.14, n.3, p.6000-6011, maio/jun, 2017. Disponível em:<http://www.nutritime.com.br/arquivosinternos /artigos/Artigo_427.pdf> Acesso em 12 de nov. de 2017. 